\title{
Numerical Method for Calculations of the Multi-Dielectric Fields Based on Flux Density in High Voltage Power Transformer Apparatus
}

\author{
N. PAMUK
}

\begin{abstract}
This paper deals with a "combination method" in which the charge simulation method is combined with finite element method, for electric field calculation. The proposed method has the advantages of both charge simulation method and finite element method, while making up of their disadvantages. In the combination method, field is divided into two regions, one covered by the charge simulation method and the other by the finite element method. These two regions are combined using the continuous conditions for potentials and dielectric flux densities at the boundary. The new method could be applied to non-enclosed multi-dielectrics fields, space charge fields, fields with leakage current and so on. Examples of calculation have revealed that the method affords satisfactory calculation accuracy in application to high voltage power transformer apparatuses.
\end{abstract}

Index Terms-Finite element analysis, Optimization, Charge simulation method, Electric field distribution, Power transformer apparatus.

\section{INTRODUCTION}

$\mathrm{T}$ HE ELECTRIC field calculation method has made a marked advance with the recent development of the computer, providing many fine results in various fields including the high voltage technique. As the major numerical electric field calculation methods, there are a charge simulation method, a finite difference method and a finite element method [1-2-3]. Each method has its own advantages and disadvantages [4-5]. For efficient calculation, the desirable method should be used according to an application field. Combining several calculation methods allows their advantages to be used and their disadvantages to be removed. This combination method can be applied to more extensive fields and will contribute to efficient calculation in many points such as accuracy and calculation time [6-7].

In order to obtain such calculation method, the author has developed the so-called combination method where the charge simulation method and the finite element method are combined. This paper describes its principle and major features, and shows that the calculation results are accurately

NIHAT PAMUK, is with Department of Electric Electronic Engineering, University of Zonguldak Bulent Ecevit University, Zonguldak, Turkey, (e-mail: nihatpamuk@beun.edu.tr / nihatpamuk@gmail.com).

iD https://orcid.org/0000-0001-8980-6913

Manuscript received August 06, 2020; accepted Oct 26, 2020.

DOI: $\underline{10.17694 / \text { bajece. } 768188}$ obtained through several examples. The combination method enables the calculation of an electric field which could not be solved with enough accuracy by individual calculation method [8-9]. For example, the combination method can be applied in non-enclosed field with multi-dielectrics, a space charge field, and a field with leakage current and so on. In addition, replacing the part of a field with another calculation method, the author can reduce the core memory requirement of computer and improve the calculation accuracy. In the following chapter, the combination method, and its calculation examples are described.

\section{Charge Simulation Method AND Finite Element METHOD}

Making use of mathematical linearly, in the charge simulation method, Laplace equation is expressed as a superposition of particular solutions such as point charges and ring charges [10]. Giving a boundary conditions, and using a concept of a potential coefficient, the author get equation 1 .

$$
P \times Q=\varnothing
$$

In equation $1, \mathrm{P}$ is a potential coefficient matrix determined by coordinates of contour point and charge point. Q is a charge vector. $\varnothing$ is a potential vector of contour points. In general, the number of this simultaneous linear equation is limited several 100 's, because of computer capacity. $\mathrm{P}$ is in general an asymmetrical matrix without a zero component. The finite element method, which allows to divide the entire field into finite elements and to assume a potential approximation function valid in each element, gives the potentials $\varnothing_{i}$ of the node points of each element so that the electrostatic energy of the entire field may become minimum [11]. If the dielectric constant of a field is $\varepsilon$, the electrostatic energy function $\mathrm{F}$ is given by equation 2 . From the minimum condition boundary is given by equation 3 . The author can get finally the equation 4 as a simultaneous linear equations.

$$
\begin{gathered}
F=\int_{V} \frac{1}{2} \varepsilon(\operatorname{grad} \emptyset)^{2} d v \\
\frac{\partial F}{\partial \emptyset_{i}}=0 \\
T \times \varnothing=B
\end{gathered}
$$


In equation $4, \mathrm{~T}$ is a total matrix of element matrices. $\varnothing$ is an unknown node potential vector. $B$ is a constant vector. It is known that the $\mathrm{T}$ matrix is a band sparse and symmetric matrix. In the finite element method, the order of T matrix can reach several 1000's in order to solve the entire field, however, its band width is about 5 to 15 , in general [12-13]. Although the charge simulation method and the finite element method are based on different principles, the similar systems of equations 1 and 4 are obtained. As shown in Table 1, both the field calculations methods have complementary features each other [14]. The development of a new field calculation method, the combination of both the above methods, allows their features to be used and the new method will be applied to an extensive technical field. On the basis of this background, the combination method has been developed. If the author once form the coupling surface between charge simulation method and finite element method regions, the author can use this surface every time when the author calculate.

TABLE I

FIELD CALCULATION BY CHARGE SIMULATION METHOD AND FINITE ELEMENT METHOD

\begin{tabular}{|c|c|c|}
\hline Features & Charge Simulation (CS) Method & Finite Element (FE) Method \\
\hline Partial Field & $\begin{array}{l}\text { The potential of a charge goes to zero at the infinite-point. } \\
\text { This enables an open space (not enclosed) and a partial field } \\
\text { to be calculated. }\end{array}$ & $\begin{array}{l}\text { In general, this method is not appropriate for the calculation of } \\
\text { a partial field. }\end{array}$ \\
\hline Boundary Shape & $\begin{array}{l}\text { Superposing the equipotential line by charges, essentially, } \\
\text { this method is appropriate for a curved form rather than a } \\
\text { straight line form. }\end{array}$ & $\begin{array}{l}\text { This method, which uses a straight line form so long as } \\
\text { making use of no isoparametric elements, is not appropriate } \\
\text { for a curved shape. }\end{array}$ \\
\hline Calculation Accuracy & $\begin{array}{l}\text { Calculation accuracy is very high. Errors on the electrodes } \\
\text { other than the contour points can become large. }\end{array}$ & $\begin{array}{l}\text { An error occurs due to approximation by finite elements of the } \\
\text { entire field. The error is a function of the number of elements. }\end{array}$ \\
\hline Multi-Dielectric Field & $\begin{array}{l}\text { As a rule, this method may be applied to the field with up to } \\
\text { two dielectrics. The method is not appropriate for the field } \\
\text { with more than two dielectrics. }\end{array}$ & $\begin{array}{l}\text { This method is not limited by the number of dielectrics and is } \\
\text { appropriate for a multi-dielectrics field. }\end{array}$ \\
\hline Thin Electrode Field & This method is not appropriate for a thin electrode. & Appropriate in a desirable manner. \\
\hline Space Charge Field & $\begin{array}{l}\text { A singular point is required to be removed by taking charge } \\
\text { distribution into consideration. Not easy. }\end{array}$ & $\begin{array}{l}\text { The solution may be easily obtained. Because of an energy } \\
\text { problem. }\end{array}$ \\
\hline Others & $\begin{array}{l}\text { Some experience is required concerning charge positions, } \\
\text { contour point positions, etc. }\end{array}$ & $\begin{array}{l}\text { This method may be universalized without experience. } \\
\text { However, an automatical data generation program is necessary } \\
\text { for input. }\end{array}$ \\
\hline
\end{tabular}

\section{NUMERICAL COMBINATION METHOD APPROACH}

In the combination method, entire field is separated into a "Charge Simulation (CS) method" region and a "Finite Element (FE) method" region. Naturally, the equation 1 applies to the (CS) region, while the equation 4 applies to the (FE) region. On the coupling surface of both regions, the entire field is combined on condition of the continuity of potential and dielectric flux density. On the coupling surface, boundary conditions are given to both regions each other. If unknowns of the entire field are given as shown in Table 2.

TABLE II

\section{UNKNOWN PARAMETERS}

\begin{tabular}{|c|l|}
\hline$n_{L}$ & Number of charges in the (CS) region \\
\hline$n_{G}$ & $\begin{array}{l}\text { Number of contour points given onto the coupling surface. } \\
\text { (Number of charges given in the coupling surface) }\end{array}$ \\
\hline$n_{G}{ }^{\prime}$ & Number of potential nodes given onto the coupling surface \\
\hline$n_{F}$ & Number of nodes in the (FE) region \\
\hline
\end{tabular}

The author get the equation 5, since the coupling points given onto the coupling surface are common to both regions. Then, the total number $\mathrm{N}$ of unknowns is shown in equation 6 .

$$
\begin{gathered}
n_{G}{ }^{\prime}=n_{G} \\
N=n_{L}+n_{F}+\left(2 . n_{G}\right)
\end{gathered}
$$

If all $\mathrm{N}$ unknowns are determined, the electric field concerning the (CS) region, may be calculated by $\mathrm{n}_{\mathrm{L}}$ charges $\mathrm{Q}_{\mathrm{L}}$ and $\mathrm{n}_{\mathrm{G}}$ charges $\mathrm{Q}_{\mathrm{G}}$, while the electric field concerning the (FE) region may be calculated by $n_{F}$ potentials $\phi_{F}$ and $n_{G}$ potentials $\phi_{\mathrm{G}}$. On the other hand the given conditions are; $\mathrm{n}_{\mathrm{L}}$ from contour point conditions in the $(\mathrm{CS})$ region, $\mathrm{n}_{\mathrm{F}}$ from the equations of energy minimal conditions in the (FE) region, and $\left(2 \times n_{G}\right)$ from potential continuity and normal component continuity of dielectric flux density on the coupling points arrayed on the coupling surface. Then the number of given conditions is $\mathrm{N}$ and the equations may be solved. Fig. 1 shows the coupling surface, coupling points arranged on the coupling surface and coupling charges corresponding to each coupling point.

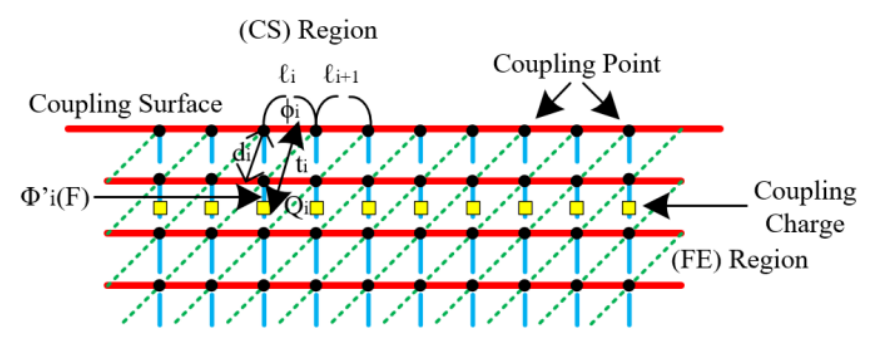

Fig.1. Coupling points and coupling charges

Let's consider the conditions which apply to coupling points. First, from the potential continuity, the author get the following equation 7 . Using the potential coefficient $P(i, j)$ and the unknown charge $\mathrm{Q}_{\mathrm{j}}, \phi_{\mathrm{i}(\mathrm{CS})}$ may be expressed as follows equation 8 .

$$
\begin{gathered}
\phi_{\dot{I}(C S)}=\phi_{\dot{I}(F E)} \quad\left(i=1 \square n_{G}\right) \\
\phi_{\dot{I}(C S)}=\sum_{j=1}^{n_{L}+n_{G}} P(i, j) \cdot Q_{J} \quad\left(i=1 \square n_{G}\right)
\end{gathered}
$$

$\phi_{\mathrm{i}(\mathrm{FE})}$ is unknown itself. From the condition that the normal 
components of dielectric flux density have continuity at the coupling points. The author get the equation 9. Further, the equation 10 is valid if the dielectric boundary is used as the coupling surface, while the equation 11 is valid if the inside of the same dielectrics is used as the coupling surface. $\mathrm{E}_{\mathrm{ni}}(\mathrm{CS})$ and $\mathrm{E}_{\mathrm{ni}(\mathrm{FE})}$ may be expressed as follows by equations 12 and 13 .

$$
\begin{gathered}
D_{n i(C S)}=D_{n i(F E)} \quad\left(i=1 \square n_{G}\right) \\
E_{n i(C S)}=\left[\frac{\varepsilon_{(F E)}}{\varepsilon_{(C S)}}\right] \cdot \quad E_{n i(F E)} \\
E_{n i(C S)}=E_{n i(F E)} \\
E_{n i(C S)}=\sum_{j=1}^{n_{L}+n_{G}} F_{n}(i, j) \cdot Q_{j} \\
E_{n i(F E)}=-\left(\frac{\phi_{i(F E)}-\phi_{i(F E)}^{\prime}}{d_{i}}\right)
\end{gathered}
$$

In the equations 9 through $13, \mathrm{n}$ indicates a normal direction, while $F_{n}(i, j)$ in the equation 12 is the field coefficient of the direction $\mathrm{n}$. di is the distance to a potential difference approximation point in the $\mathrm{i}$-th coupling point, which is shown in Fig. 1. In Fig.1, the distance $t$ from a coupling point to a coupling charge is generally expressed as a function of the distance $\ell$ between coupling points. Thus, the author get the equation 14. In equation $14, \mathrm{k}$ is a constant.

$$
t_{i}=k \cdot \ell_{i}
$$

Fig. 2 shows the combination matrix constructed in such manner and the configuration of simultaneous linear equations. In the matrix of Fig. 2, the portions indicated by oblique lines are asymmetrical matrices without zero component. The entire combination matrix is asymmetric and a bad-status matrix with many zero elements.

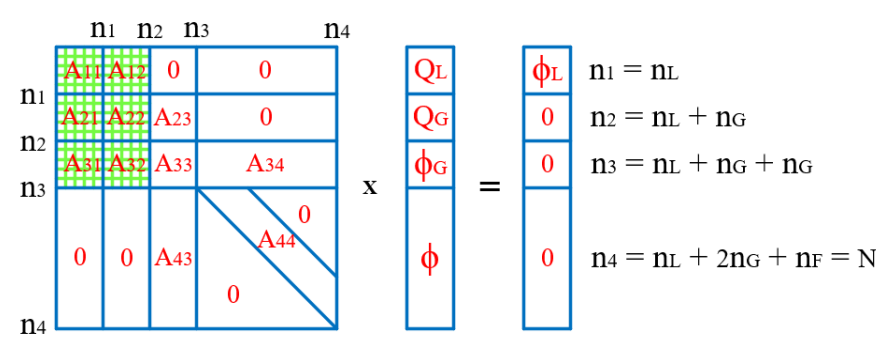

Fig.2. Combination matrix and configuration of simultaneous linear equations

\section{DISCUSSION}

The combination method is applied to the two dimensional two-dielectric field where a cylinder and a grounded plane are used as electrodes as shown in Fig. 3 and calculation results are examined. The cylinder potential is to be $100 \%$ and the plane potential is to be $0 \%$ [15]. First, the dielectric field boundary is considered to be a coupling surface for both the calculation method regions and the dielectric field constant ratio is to be $1.0-3.0$ [16]. Nine $\left(\mathrm{n}_{\mathrm{L}}\right)$ infinite line charges were arranged in the high voltage power transformer apparatus cylinder electrode and calculation was made by setting the coupling point conditions as a parameter. A program is available so that, in each element in the (FE) region, first and second polynomials may be used as a potential approximation function. To make the element in (FE) region, an automatically grid generation program was introduced.

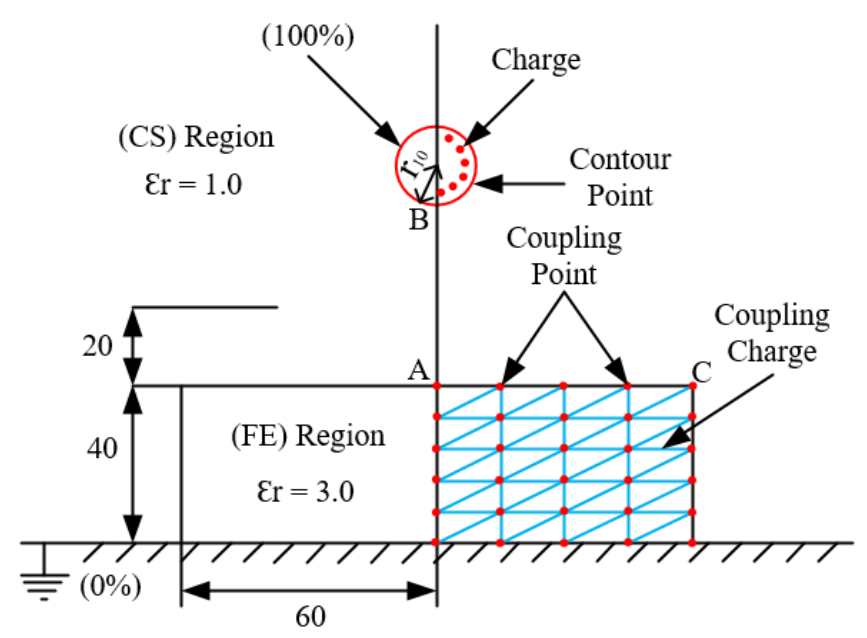

Fig.3. Calculation example of 2D-dimensional and 2D-dielectric field

Table 3 shows calculation results of the potential and electric field strength of the point A and electric field strength of the point B in high voltage power transformer apparatus. Calculation results using charge simulation method by 330 charges on the same electrode configuration are shown in this table for comparison. Calculation results of the potential and electric field strength of the point A (in Fig. 3) and of the electric field strength of the point $\mathrm{B}$ when $\mathrm{k}$ in the equation 14 is equal to 1 and $\ell_{\mathrm{i}} / \ell_{\mathrm{i}+1}$ is equal to 1.0 in Fig. 1 .

TABLE III

CALCULATION RESULTS USING CHARGE SIMULATION METHOD

\begin{tabular}{|c|c|c|c|}
\hline $\mathrm{n}_{\mathrm{G}}$ & $\begin{array}{c}\text { Potential at } \\
\text { point A }\end{array}$ & $\begin{array}{c}\text { Electric field } \\
\text { strength at point A }\end{array}$ & $\begin{array}{c}\text { Electric field } \\
\text { strength at point B }\end{array}$ \\
\hline 8 & $29.60264(\mathrm{pu})$ & $2.57639(\mathrm{pu})$ & $5.89505(\mathrm{pu})$ \\
\hline 12 & $28.60814(\mathrm{pu})$ & $2.62808(\mathrm{pu})$ & $5.98226(\mathrm{pu})$ \\
\hline 16 & $28.19811(\mathrm{pu})$ & $2.65422(\mathrm{pu})$ & $5.95752(\mathrm{pu})$ \\
\hline 20 & $27.97338(\mathrm{pu})$ & $2.66892(\mathrm{pu})$ & $5.99580(\mathrm{pu})$ \\
\hline 24 & $27.83155(\mathrm{pu})$ & $2.67823(\mathrm{pu})$ & $6.00434(\mathrm{pu})$ \\
\hline 28 & $27.73378(\mathrm{pu})$ & $2.68464(\mathrm{pu})$ & $6.01023(\mathrm{pu})$ \\
\hline 32 & $27.66252(\mathrm{pu})$ & $2.68931(\mathrm{pu})$ & $6.01452(\mathrm{pu})$ \\
\hline 36 & $27.60785(\mathrm{pu})$ & $2.69288(\mathrm{pu})$ & $6.01782(\mathrm{pu})$ \\
\hline 40 & $27.56525(\mathrm{pu})$ & $2.69566(\mathrm{pu})$ & $6.02038(\mathrm{pu})$ \\
\hline 44 & $27.53046(\mathrm{pu})$ & $2.69793(\mathrm{pu})$ & $6.02249(\mathrm{pu})$ \\
\hline 48 & $27.50130(\mathrm{pu})$ & $2.69981(\mathrm{pu})$ & $6.02426(\mathrm{pu})$ \\
\hline 52 & $27.47723(\mathrm{pu})$ & $2.70137(\mathrm{pu})$ & $6.02572(\mathrm{pu})$ \\
\hline 56 & $27.45629(\mathrm{pu})$ & $2.70272(\mathrm{pu})$ & $6.02700(\mathrm{pu})$ \\
\hline 60 & $27.43821(\mathrm{pu})$ & $2.70388(\mathrm{pu})$ & $6.02810(\mathrm{pu})$ \\
\hline 64 & $27.42243(\mathrm{pu})$ & $2.70489(\mathrm{pu})$ & $6.02906(\mathrm{pu})$ \\
\hline $\begin{array}{c}\text { By }(\mathrm{CS}) \\
\text { method }\end{array}$ & $27.23134(\mathrm{pu})$ & $2.71510(\mathrm{pu})$ & $6.04001(\mathrm{pu})$ \\
\hline 330 & & & \\
charges & & & \\
\hline
\end{tabular}

Error of potential at point $\mathrm{A}$ is shown in Fig. 4. Error of field strength at point A is shown in Fig. 5. Figs. 4 and 5 show calculation errors indicated as a function of the number $n_{G}$ of 
coupling points. As the number of coupling points increase, calculation errors decrease.

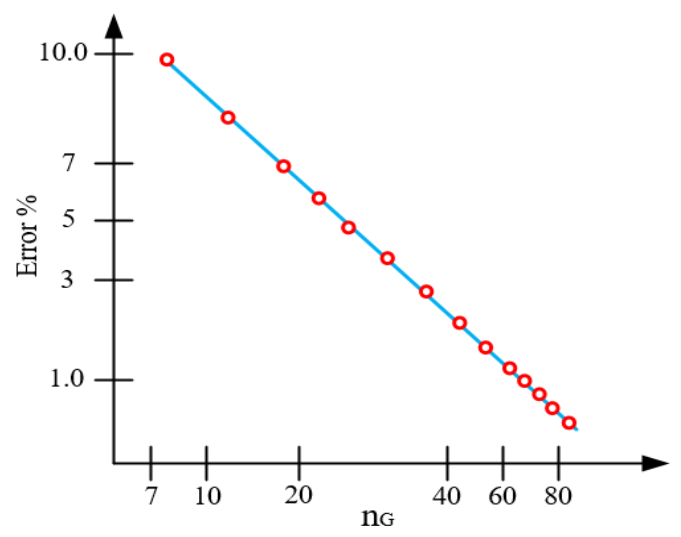

Fig.4. Error of potential at point A

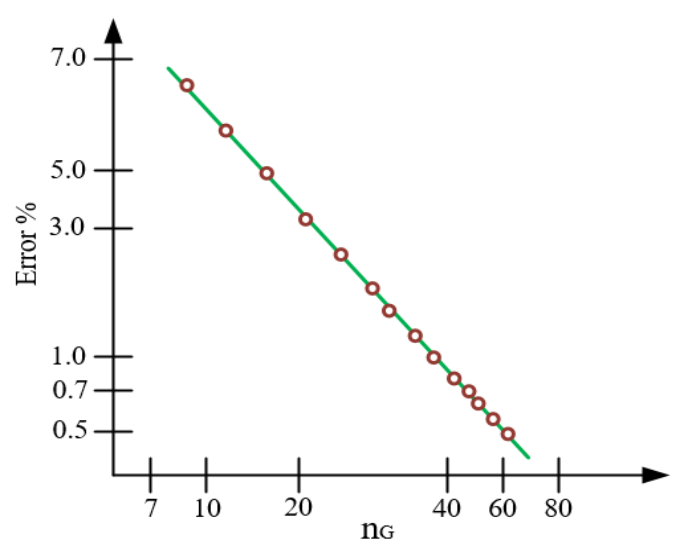

Fig.5. Error of field strength at point A

Fig. 6 shows that the electric field strength at the point $A$ is indicated as a function of the number of elements in the finite element method region. The calculation results by using first and second order polynomials in (FE) region is shown for comparison.

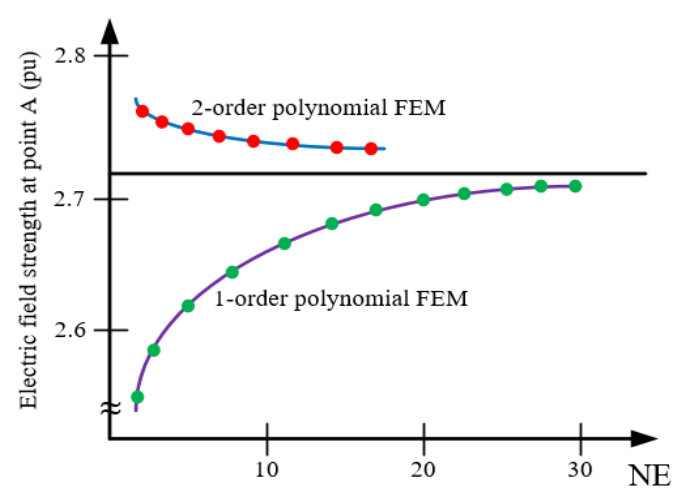

Fig.6. Field strength as function of (NE)

Fig. 7 shows the electric field strength of the point $\mathrm{A}$ as a function of $\mathrm{k}$ in equation 14 , where $\mathrm{n}_{\mathrm{G}}$ is kept constant. If $\mathrm{n}_{\mathrm{G}}$ is to be 64 and the coupling points are distributed in geometrical progression, it is revealed that calculation errors are not more than $0.2 \%$ for the potential and $0.1 \%$ for the electric field strength at the point $\mathrm{A}$. The above calculation results reveal that calculation accuracy is a function of the number $n_{G}$ of coupling points and if the author apply this method to high voltage technique, the author can get satisfactory calculation results. The point $\mathrm{C}$ in Fig. 3 is a singular point and it is assumed that calculation errors increase in the vicinity of the point $\mathrm{C}$.

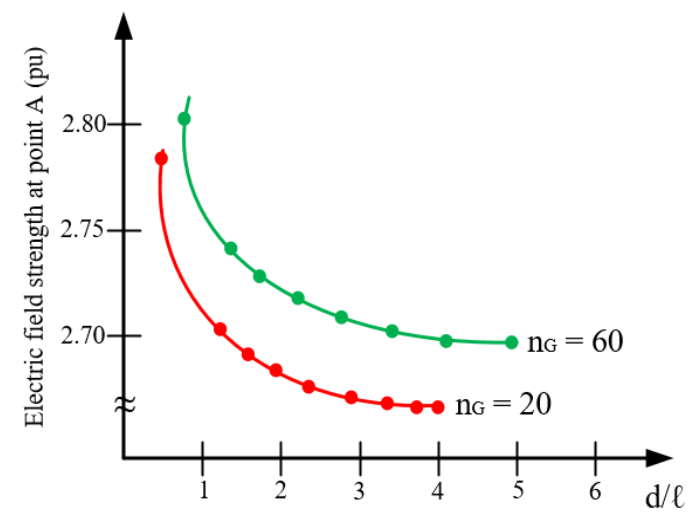

Fig.7. Field strength as function of $(d / \ell)$

Fig. 8 shows an example of equipotential lines of 2D dimensional electric field. The solid lines are obtained by using the coupling surface $\mathrm{X}$, while the dotted lines are obtained by using the dielectric boundary as the coupling surface. The dotted lines show discontinuity at the equipotential line at point $\mathrm{P}$.

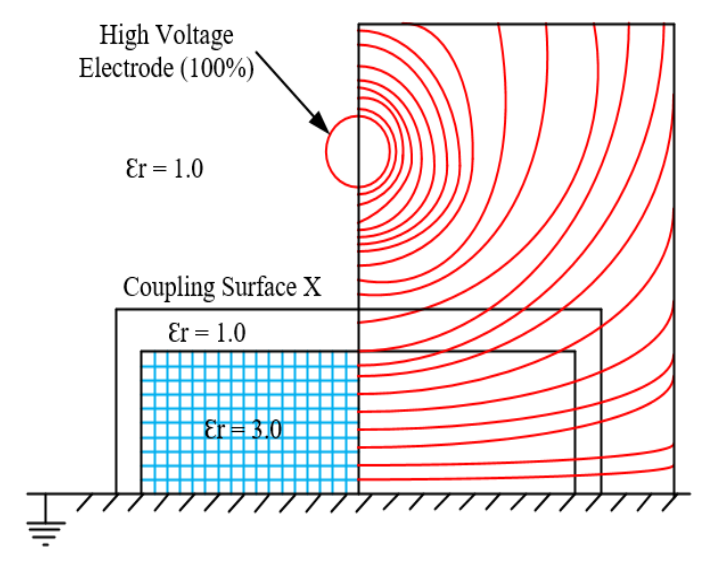

Fig.8. Equipotential lines of 2D dimensional electric field

Fig. 9 shows a mesh in (FE) region. Fig. 10 shows a dielectric two flat plate field.

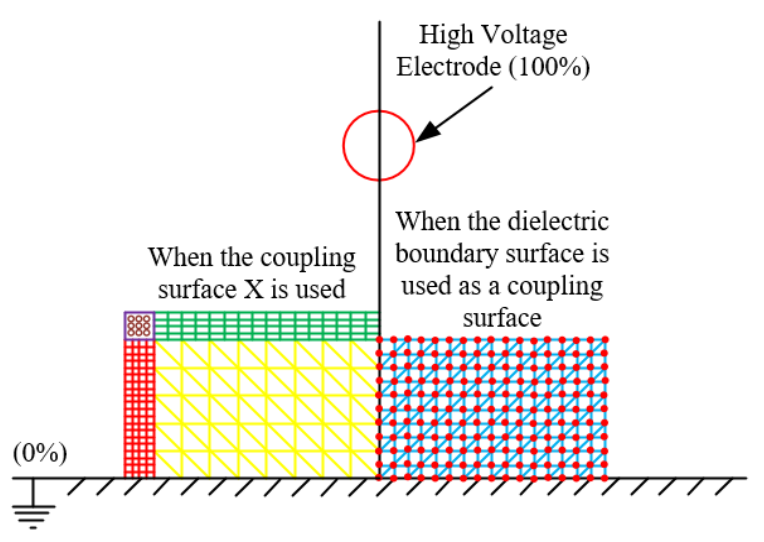

Fig.9. Mesh of elements in FE method 


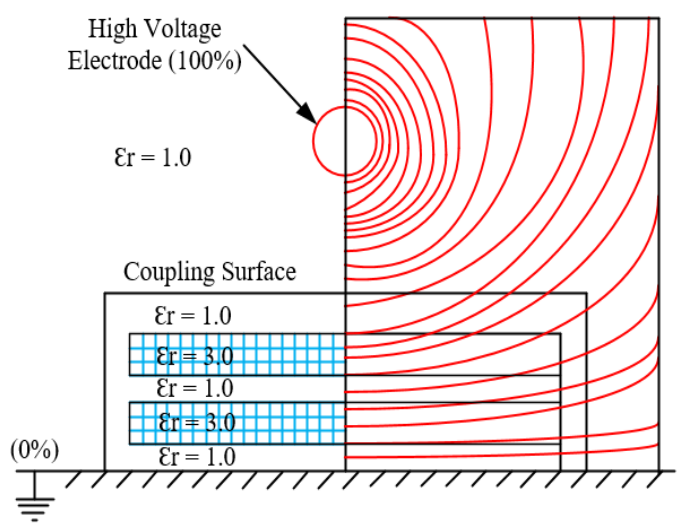

Fig.10. Calculation example dielectric flat-plate field

It is obviously shown that once formed the coupling surface between (CS) and (FE) region may be applied to various kinds of fields. Even if there are space charges or surface charges, namely the Poisson field, the combination method can be easily applied. As shown in Fig. 11, the equipotential lines are evidently distorted if space charges are distributed in the thin space on the dielectric plate.

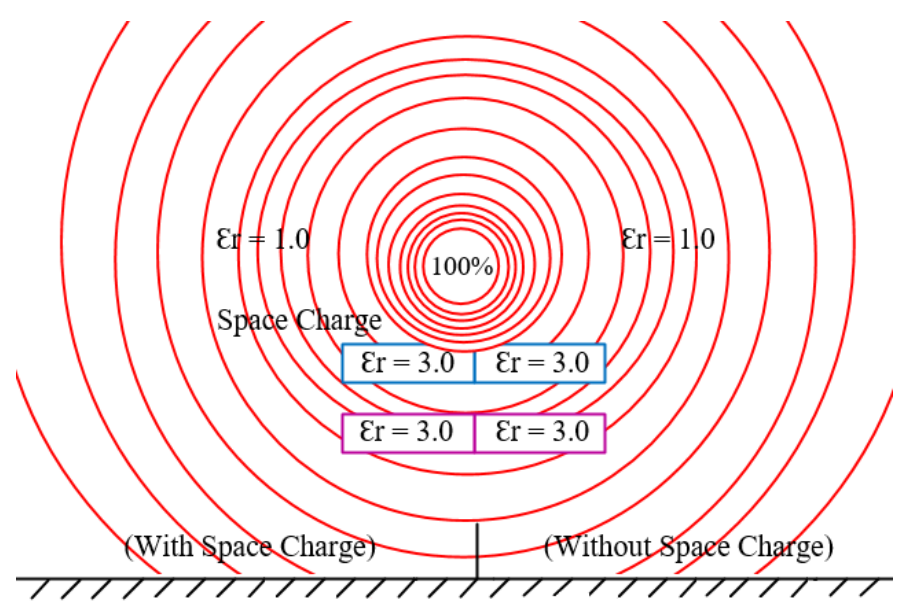

Fig.11. Calculation example of space charge field

In that case, $\mathrm{F}^{\prime}$ is used as an energy functional that is valid in the (FE) region. F' may be expressed as follows by equation 15. In equation $15, \rho$ is the charge gratuity. The combination method may be also applied to a field with surface or volume leakage current.

$$
F^{\prime}=\iiint\left(\frac{1}{2} \varepsilon \cdot(\operatorname{grad} \phi)^{2}-\rho \phi\right) d v
$$

Finally, Fig. 12 shows calculation results of equipotential lines when the combination method is applied to an axisymmetric three (3D) dimensional electric field. The principles of the coupling surface are the same as those in the two (2D) dimensional electric field. Ring charges are used in the (CS) region. The calculation of three (3D) dimensional axisymmetric multi dielectric field in the high voltage power transformer apparatus as shown in Fig. 12. The Fig. 12 consists of four dielectric fields of air, glass, insulating oil and oil-impregnated paper and is non-enclosed field in the high voltage power transformer. Therefore, it is difficult to solve the electric field by the optimization theory based on charge simulation method or the finite element method, if they are used individually.

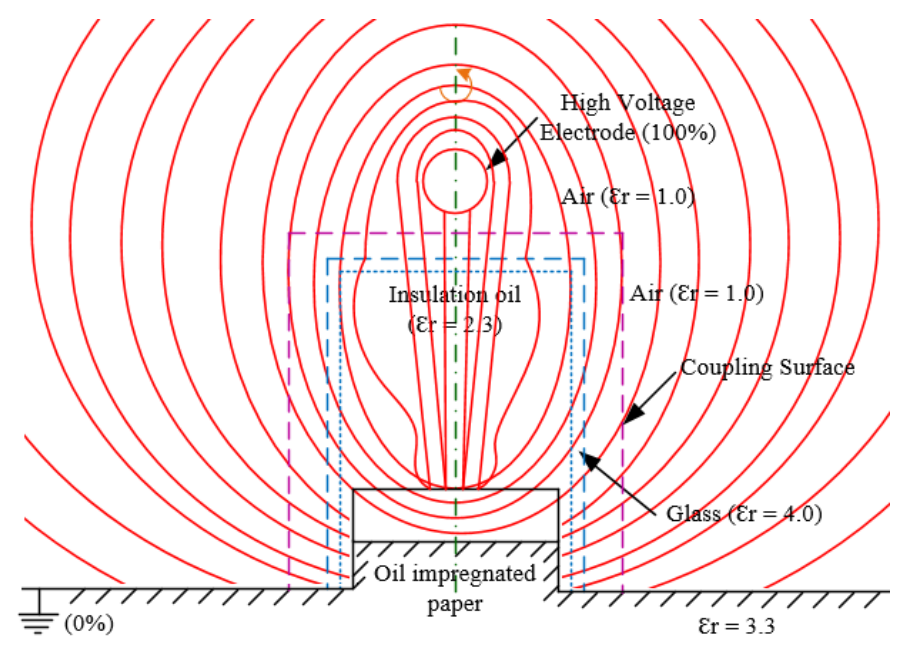

Fig.12. Calculation of 3D dimensional axisymmetric multi dielectric field

\section{CONCLUSION}

As described above, the so-called combination method that combines the optimization theory based on charge simulation method and the finite element method has the following features. Calculation accuracy required to the high voltage power transformer apparatuses is fully met. Calculation accuracy depends on the relationship of the number of coupling points placed on the coupling surface between the (CS) and (FE) region. Using a high order polynomials allows high accuracy to be obtained in less coupling points. The coupling surface is proper to not only a dielectric boundary but also any other space. If a dielectric boundary is complicated, it is recommended for easier calculation that any other space should be used as the coupling surface. This method may be applied to non-enclosed field, a complicated dielectric field, a space-charge field, etc. If the coupling surface is once formed, the combination method can be applied easily to any other field to be calculated.

\section{REFERENCES}

[1] M.M. Abouelsaad, M.A. Abouelatta, A.E.R. Salama. "Genetic algorithm-optimized charge simulation method for electric field modelling of plate-type electrostatic separators." IET Science, Measurement \& Technology, vol. 7. 1, 2013, pp 16-22.

[2] K. Nishimura, K. Nishimori. "Arrangement of fictitious charges and contour points in charge simulation method for electrodes with 3D asymmetrical structure by immune algorithm." Journal of Electrostatics, vol. 63. 6-10, 2005, pp 743-748.

[3] N.H. Malik. "A review of the charge simulation method and its applications." IEEE Transactions on Electrical Insulation, vol. 24. 1, 1989, pp 3-20.

[4] X. Liu, Y. Cao, E. Wang. "Numerical simulation of electric field with open boundary using intelligent optimum charge simulation method." IEEE Transactions on Magnetics, vol. 42. 4, 2006, pp 1159-1162.

[5] A. Ranković, M.S. Savić. "Generalized charge simulation method for the calculation of the electric field in high voltage substations." Electrical Engineering, vol. 92. 2, 2010, pp 69-77.

[6] W. Krajewski. "Numerical modelling of the electric field in HV substations." IEE Proceedings-Science, Measurement and Technology, vol. 151. 4, 2004, pp 267-272. 
[7] S. Nikolovski, P. Maric, Z. Baus. "Electromagnetic field calculation of transformer station 400/110Kv Ernestinovo using the CDEGS software." Journal of Electrical Engineering-Bratislava, vol. 58. 4, 2007, pp 207-213.

[8] T. Lu, H. Feng, Z. Zhao, X. Cui. "Analysis of the electric field and ion current density under ultra-high-voltage direct current transmission lines based on finite element method." IEEE Transactions on Magnetics, vol. 43. 4, 2007, pp 1221-1224.

[9] D. Stefanini, J.M. Seifert, M. Clemens, D. Weida, "Three Dimensional FEM Electrical Field Calculations for EHV Composite Insulator Strings." IEEE International Power Modulator and High Voltage Conference, 23-27 May 2010. Atlanta, GA, USA, 2010.

[10] C. Lu, Z. Yang, J. Bai, Y. Cao, X. He. "Three dimensional immersed finite element method for anisotropic magnetostatic/electrostatic interface problems with nonhomogeneous flux jump." International Journal for Numerical Methods in Engineering, vol. 121. 10, 2020, pp 2107-2127.

[11] L.J. Gomez, M. Dannhauer, L.M. Koponen, A.V. Peterchev. "Conditions for numerically accurate TMS electric field simulation." Brain Stimulation, vol. 13. 1, 2020, pp 157-166.

[12] A.T. Htet, G.B. Saturnino, E.H. Burnham, G.M. Noetscher, A. Nummenmaa, S.N. Makarov. "Comparative performance of the finite element method and the boundary element fast multipole method for problems mimicking transcranial magnetic stimulation (TMS)." Journal of Neural Engineering, vol. 16. 2, 2019, 024001.

[13] Q. Tan, Q. Xu, L. Chen, Y. Huang. "A new method to improve internal electric field distributions of pockels OVS." IEEE Sensors Journal, vol. 17. 3, 2017, pp 4115-4121.

[14] K.H. Lee, S.G. Hong, M.K. Baek, H.S. Choi, Y.S. Kim, I.H. Park. "Alleviation of electric field intensity in high voltage system by topology and shape optimization of dielectric material using continuum design sensitivity and level set method." IEEE Transactions on Magnetics, vol. 51. 3, 2015, pp 1-4.

[15] Y.N. Zhao, G.Q. Zhang, Z.Z. Guo, S. Cheng. "The mathematical model of electrical field distribution in optical voltage transformer." Procedia Engineering, vol. 29. 1, 2012, pp 2661-2666.

[16] S.L. Ho, N. Chen, W.N. Fu. "A moving mesh embedded algorithm in finite element method for optimal design of electromagnetic devices." IEEE Transactions on Magnetics, vol. 47. 10, 2011, pp 2947-2950.

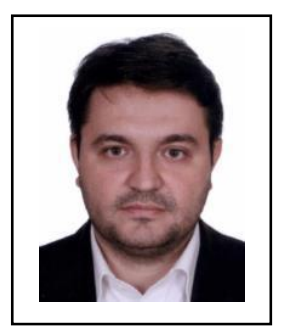

\section{BIOGRAPHY}

NIHAT PAMUK is an Associate Professor, of Department of Electrical Electronics Engineering in Zonguldak Bulent Ecevit University. He received his bachelor's degree in electric electronics engineering department from Firat University, Turkey, in 2005. He completed his MSc and $\mathrm{PhD}$ degrees all in electric electronics engineering department from Sakarya University, Turkey in 2009 and 2012 respectively. His research interests are power system analysis, power protection systems, high voltage transmission and switch gears devices, renewable energy, smart grids and power quality. 